\title{
Association between swimming performance, cardiorespiratory morphometry, and thermal tolerance in Atlantic salmon (Salmo salar L.)
}

\section{Katja Anttila ${ }^{1+}$, Sven Martin Jørgensen ${ }^{2+}$, Matthew T. Casselman $^{3}$, Gerrit Timmerhaus $^{2}$, Anthony P. Farrell ${ }^{3,4}$ and Harald Takle ${ }^{2 *}$}

${ }^{1}$ Laboratory of Animal Physiology, Department of Biology, University of Turku, Turku, Finland

2 Nofima AS, Ås, Norway

${ }^{3}$ Department of Zoology, University of British Columbia, Vancouver, BC, Canada

${ }^{4}$ Faculty of Land and Food Systems, University of British Columbia, Vancouver, BC, Canada

\section{Edited by:}

Josep V. Planas, University of

Barcelona, Spain

Reviewed by:

Anthony K. Gamperl, Memorial University of Newfoundland, Canada

Helgi Thorarensen, Hólar University

College, Iceland

*Correspondence:

Harald Takle, Nofima AS, NO-1431,

Osloveien 1, Ås, Norway

e-mail: harald.takle@nofima.no

${ }^{\dagger}$ Co-first authors.
This experiment tested the hypothesis that swimming performance in Atlantic salmon (Salmo salar) parr is connected to cardiorespiratory performance and morphology, as well as maximum heart rate $\left(f_{H \max }\right)$ related measures of thermal tolerance. Moreover, it was hypothesized that the cardiorespiratory differences between poor and strong swimmers will be retained in a later life stage, i.e., 15 weeks post-smoltification and seawater transfer. This experiment screened a population of 3200 parr $(11.2 \pm 0.25 \mathrm{~g})$ for their swimming performance, classifying them as poor and good swimmers based on their critical swimming speeds $\left(4.4 \pm 0.1\right.$ body length $s^{-1}$ and $>6.8 \pm 0.1$ body length $s^{-1}$, respectively). Compared with poor performing parr, good swimmers had a significantly thicker compact myocardium (by $23.7 \%$ ) and taller gill secondary lamellae (by $16.2 \%)$. In contrast, there was no significant difference in maximum oxygen consumption between the two groups as assessed using a "chase" protocol, and the relationship between heart rate specific measures of thermal tolerance and swim performance was variable. For example, three measures did not differ between the two groups, whereas the Arrhenius breakpoint temperature for $f_{H \max }$ and the highest $f_{H \max }$ value were lower and higher, respectively, in the poor swimmers. Importantly, the identified morphological and difference in the highest $f_{H \max }$ value at the parr stage persisted after 15 weeks of common garden rearing in seawater, and they were associated with an increase in relative ventricular mass and a small, but significant, improvement in growth rate. Therefore, it seems that an early assessment of swimming performance can effectively screen for morphological capacities related to oxygen supply and growth rate, but less so for heart rate related measures of thermal tolerance.

Keywords: screening fish, compact myocardium, swimming endurance, gill lamellae, optimum temperature, relative ventricle mass, maximum heart rate, oxygen consumption

\section{INTRODUCTION}

A formidable challenge for the salmon aquaculture industry is $10-20 \%$ mortality that occurs after smolts are introduced to sea cages. While much of the mortality is attributed to infectious and non-infectious diseases, fish in poor condition are often observed in sea-cages following smolt transfer and handling stress. These weaker individuals are assumed to be more susceptible for pathogens (Specker and Schreck, 1980; Iversen et al., 2005; Kristensen et al., 2012a). Central to the present study is the suggestion that an enriched rearing environment and training or conditioning early in parr development and prior to transfer to seawater could benefit the survival of farmed smolts (Anttila et al., 2011; Hyvärinen and Rodewald, 2013; Takle and Castro, 2013). This suggestion builds on the fact that swimming performance and cardiorespiratory physiology are plastic and appropriate exercise training programs have been shown to improve swimming capacity (Farrell et al., 1990; Davison, 1997; Gamperl and Farrell,
2004; Anttila et al., 2008), cardiac capacity (Farrell et al., 1991; Gallaugher et al., 2001; Castro et al., 2013a), and disease resistance (Castro et al., 2011, 2013a) of farmed fish.

Moreover, cardiorespiratory traits tend to show associations with each other. For example, swimming capacity correlates with cardiac capacity and oxygen transport capacity (Claireaux et al., 2005). Also, these traits are known to be important factors for lifetime fitness of wild salmon (Eliason et al., 2011, 2013), especially when extremely warm temperatures are concerned (Farrell, 2009; Eliason et al., 2011). Furthermore, cardiac morphology in farmed trout and salmon is distinct to wild conspecifics (Poppe et al., 2003; Gamperl and Farrell, 2004; Kristensen et al., 2012b). As a result, the Atlantic salmon aquaculture industry is searching for screening tools to improve the cardiac capacity of the smolts they chose for grow-out because better robustness could enhance survival and growth. Therefore, the purpose of the present investigation was to sort a population of 3200 Atlantic salmon parr 
on their swimming performance and test the hypothesis that their swimming performance is connected to cardiorespiratory performance and morphology, as well as upper thermal tolerance. Furthermore, we examined whether or not any identified differences were retained into the critical post-smolt stage in seawater.

To test our hypothesis, we measured growth, indices of swimming performance, gill, and cardiac morphometry (e.g., ventricular mass, compact myocardium thickness, and gill lamellae height $)$ and the response of maximum heart rate $\left(f_{\text {Hmax }}\right)$ to acute warming before and after seawater transfer. While ventricular mass and gill lamellae height provide well-established indices of cardiorespiratory capacity, the comparison between rate transition temperatures for $f_{\text {Hmax }}$ and swimming performance is novel. The rationale for selecting $f_{\text {H max }}$ for the comparisons is that $f_{\text {Hmax }}$ is a useful tool to rapidly characterize the upper temperature performance of small fishes. Heart rate $\left(f_{H}\right)$ is the key cardiovascular response of fish to warming. Specifically, at temperatures beyond the optimal temperature $\left(\mathrm{T}_{\mathrm{opt}}\right)$ for aerobic scope (difference between resting and maximum metabolic rate; Fry, 1947), $f_{H}$ either reaches its maximum or begins to decrease (even becoming arrhythmic; Steinhausen et al., 2008; Sandblom et al., 2009; Eliason et al., 2011; Gamperl et al., 2011) and acts as a trigger for aerobic scope to fail (Farrell, 2009). Although not providing as much information as aerobic scope on the maximum capacity for energy availability for growth, swimming and immune defense (Pörtner and Farrell, 2008; Pörtner, 2010), associations are wellestablished between rate transition temperatures for $f_{\text {Hmax }}$ and upper thermal tolerance indices for a variety of fish species, including a range of salmonids [e.g., coho salmon (Oncorhynchus kisutch), Casselman et al., 2012; rainbow trout (Oncorhynchus mykiss), Anttila et al., 2013a; sockeye salmon (Oncorhynchus nerka), Chen et al., 2013; pink salmon (Oncorhynchus gorbuscha), Clark et al., 2011].

\section{MATERIALS AND METHODS}

All procedures were approved by the National Animal Research Authority according to the "European Convention for the Protection of Vertebrate Animals used for Experimental and other Scientific Purposes" (EST 123).

\section{EXPERIMENTAL FISH AND REARING CONDITIONS}

Fish rearing and testing were conducted at the Nofima research station, Sunndalsøra, Norway. Fertilized Atlantic salmon (Salmo salar L., Bolaks strain) eggs were received from SalmoBreed AS (Bergen, Norway) at 386 day degrees and incubated at $7-8^{\circ} \mathrm{C}$ until hatching. In March 2013, emergent fry started feeding and temperature was progressively increased to $12^{\circ} \mathrm{C}$ according to industry standards. In May 2013, 3 weeks prior to swimming experiments, 3200 fish were selected within a narrow size range (to limit the variance in body mass to $\pm 2 \mathrm{~g}$ ) and moved to a single circular fiberglass tank ( $3 \mathrm{~m}$ diameter, $0.75 \mathrm{~m}$ water depth) supplied with the same water quality and temperature and reared under standard conditions (constant light, 85-100\% oxygen saturation) with ad libitum feeding of a commercial feed (Skretting, Stavanger, Norway). The fish were sorted into poor and good swimmers according to swimming performance (as described below), and their maximum heart rate $\left(f_{\text {Hmax }}\right)$ and metabolic rates were measured in June. Thereafter, the fish were kept in separate tanks for 4 weeks before being individually tagged (passive integrated transponder tag, Jojo Automasjon AS, Sola, Norway), measured for length and body mass before being reared in a single, common-garden tank during the smoltification period (short daylight period of 12:12 LD for 6 weeks followed by continuous light for 4 weeks). When the smolts were ready for seawater transfer by mid-September (according to standard smolt-tests), they were all re-measured for length and body mass and 100 good (average body mass $78 \pm 7.4 \mathrm{~g}$ ) and 100 poor (average body mass $76 \pm 7.3 \mathrm{~g}$ ) swimmers were selected for transport to the VESO Vikan Research Station (Vikan, Norway). At the research station fish were reared in seawater (25\% salinity) for 15 weeks in a common garden aquarium (a single $1.5 \mathrm{~m}$ circular fiberglass tank) using standard culture conditions [flow through, $12^{\circ} \mathrm{C},>80 \%$ oxygen saturation, $2 \%$ daily feeding of commercial feed (Skretting)]. In January 2014, the fish were again tested for length and body mass, and tested for maximum heart rate performance.

\section{THE SCREEN FOR SWIMMING PERFORMANCE OF PARR}

Swimming performance of 3200 parr was screened at $12^{\circ} \mathrm{C}$ in June 2013 after they had been starved for $24 \mathrm{~h}$. Each screening test used 400 fish divided equally in two modified Brett-type swim tunnels supplied with the water of the same quality and temperature as the rearing tank. Therefore, the swimming performance was estimated for 16 batches of 200 fish. Each swim tunnel was composed of a $2 \mathrm{~m}$ long transparent PVC swim chamber with an inner diameter of $20 \mathrm{~cm}$ mounted in a leveled stainless steel frame. Each swim tunnel (approximate volume of $63 \mathrm{~L}$ ) was supplied with water from an open fiberglass reservoir tank $\left(7 \mathrm{~m}^{3}\right)$ via a 424 L closed polyethylene tank. The pump (VAKI Heathro Self Priming 6" pump, VAKI Aquaculture Systems Ltd., Kópavogur, Iceland) supplying the water was controlled by a Cubix remote controller (HBC-radiomatic $\mathrm{GmbH}$, Crailsheim, Germany). A laminar flow grid was also positioned in front of each swim chamber. The rear of each swim tube was connected to an external sling slip tee pipe, which drained the water back to open reservoir via a customized net to remove fish as they fatigued and no longer maintained station in the swim chamber. Water velocity was measured using a Micronics Portaflow 300 ultrasonic flow meter (Micronics Ltd., Buckinghamshire, UK). The swim protocol consisted of 30-min habituation to a low water velocity of 0.5 body lengths per second $\left(B L \mathrm{~s}^{-1}\right)$. The fish were exposed to an incremental acceleration protocol that is thought to estimate critical swimming speed reasonably well (Farrell et al., 2003). The protocol consisted of a stepwise increase of $0.5 B L \mathrm{~s}^{-1}$ every minute up to $3 \mathrm{BL} \mathrm{s}{ }^{-1}$, which was maintained for $5 \mathrm{~min}$ before increasing the speed to $4 B L \mathrm{~s}^{-1}$ to position the fish in main water current. This speed was maintained until no more fish fatigued for a period of $10 \mathrm{~min}$; fatigued fish were removed when they fell back into the net. Then the water speed was increased $0.5 \mathrm{BL}$ $\mathrm{s}^{-1}$ every $5 \mathrm{~min}$ until only $30 \%$ of the fish remained swimming, which were termed good swimmers. This speed was noted and the $30 \%$ best swimmers were then given an enhanced and rapid acceleration ( $1 \mathrm{BL} \mathrm{s}^{-1}$ every $1 \mathrm{~min}$ ) to remove them from the 
swim chambers as they fatigued. The maximum velocity swum by the best swimmers was $1.2 \mathrm{~m} \mathrm{~s}^{-1}$ and the performance is simply reported as $>6.78 \mathrm{BL} \mathrm{s}^{-1}$. The first $30 \%$ of fish to fatigue were termed poor swimmers and the next $40 \%$ were termed moderate swimmers. After screening, all fish were fin clipped and good and poor swimmers were transferred to a new tank supplied with the same water as the holding tank for recovery. Parr recovered for at least 3 days after screening of swimming performance before the tests of $f_{\text {Hmax }}$ and respirometry measurements were started. No mortality occurred during the 2-month rearing period following the swimming screen.

Swimming fish in bulk is the only practical way to screen swimming performance for a population of fish. While the intent was to measure swimming capacity, we cannot exclude the possibility that behavior and the willingness to swim were a component of this assessment (e.g., see Peake and Farrell, 2005, 2006; Farrell, 2007).

\section{MAXIMUM HEART RATE MEASUREMENT IN PARR}

The response of $f_{\text {Hmax }}$ to acute warming was measured for 12 poor and 12 good swimmers (tested in a randomized order) as described by Casselman et al. (2012) with slight modifications. Briefly, each fish was first lightly anesthetized with $100 \mathrm{ppm}$ MS-222 (buffered with sodium bicarbonate to $\mathrm{pH}$ 7.0) and weighed before placing it fully immersed in an experimental chamber that received temperature-controlled $\left(11^{\circ} \mathrm{C}\right)$ aerated water from a Julabo circulating chiller/heater (F32 ME, Julabo $\mathrm{GmbH}$, Seelbach, Germany). The circulating water, which contained 60 ppm buffered MS-222, was partially directed over the gills to maintain an anesthetized state throughout the whole experiment. An electrocardiogram (ECG) was recorded with a chromel-A measuring electrode positioned lightly on the skin just below the heart and a reference electrode positioned caudal to the heart. The ECG signal was amplified $(1000 \times$, Grass P55 amplifier, Astro-Med, Brossard, QC, Canada) and filtered ( $50 \mathrm{~Hz}$ line filter; low-pass: $30 \mathrm{~Hz}$; high-pass: $0.3 \mathrm{kHz}$ ) before being stored in a PowerLab data acquisition system (PL3508, PowerLab 8/35, AD Instruments Ltd., Oxford, UK). Heart rate was allowed to stabilize for $30 \mathrm{~min}$ at $11^{\circ} \mathrm{C}$ before an intraperitoneal injection of atropine sulfate $\left(2.4 \mathrm{mg} \mathrm{kg}^{-1}\right.$ dissolved in $0.9 \% \mathrm{NaCl}$; Sigma-Aldrich, Oslo, Norway) that blocked vagal inhibition of the heartbeat. Preliminary tests showed that an isoproterenol injection did not increase $f_{H}$ at any temperature as previously shown for Atlantic salmon (Anttila et al., 2014). Similarly, Casselman et al. (2012) found that isoproterenol increased $f_{H}$ by only 0.3 beats $\min ^{-1}$ in MS-222 anesthetized coho salmon. Water temperature was increased in $1^{\circ} \mathrm{C}$ increments for a cumulative warming rate of $10^{\circ} \mathrm{C} \mathrm{h}^{-1}$, beginning $15 \mathrm{~min}$ after the atropine injection. At each temperature increment both the water temperature and $f_{\text {H max }}$ were stable. $f_{H \max }$ was recorded at each temperature increment by counting R-R intervals for final 15 heartbeats before another temperature increment. The incremental heating was terminated at the temperature when cardiac arrhythmias were first observed (QRS complex or P wave was missing) at which time the fish was quickly removed from chamber and euthanized by blow to the head prior to tissue sampling.

\section{OXYGEN CONSUMPTION MEASUREMENTS OF PARR}

Resting and maximum oxygen consumption rate $\left(\mathrm{MO}_{2}\right)$ measurements were performed on 10 poor and 10 good swimming fish (alternating tests). Each fish was transferred in the evening into either a $3.52 \mathrm{~L}$ Loligo swim tunnel respirometer (Loligo Systems ApS, Tjele, Denmark) or a 3.10 L respirometry chamber that were immersed in a water bath supplied with fresh water from the same source as the rearing tanks. Water in each chamber was continuously re-circulated and temperature in the chambers maintained at $12^{\circ} \mathrm{C}\left( \pm 0.5^{\circ} \mathrm{C}\right)$ for the duration of the experiments. After $1 \mathrm{~h}$, while the fish adjusted to the chamber and recovered from handling, chambers were automatically cycled between being sealed for oxygen measurements $(0.25 \mathrm{~h})$ and being open for flushing $(0.75 \mathrm{~h})$. Thus, $\mathrm{MO}_{2}$ was measured repeatedly overnight. Oxygen concentration $\left(\mathrm{mg} \mathrm{L}^{-1}\right)$ was measured using an OXROB10 optical oxygen probe connected to a FireStingO2 oxygen meter (PyroScience GmbH, Aachen, Germany). Oxygen probes were calibrated daily. Blank runs without fish confirmed that background oxygen removal from the respirometer was negligible.

Maximum $\mathrm{MO}_{2}$ measurements were performed during the following morning. Each fish was removed from its respirometer and transferred to $10 \mathrm{~L}$ chase tank. Fish were exhaustively exercised in the chase tank for $3 \mathrm{~min}$ and then air exposed for $1 \mathrm{~min}$ to ensure exhaustion. Fish were immediately transferred to a custom $0.27 \mathrm{~L}$ respirometry chamber and oxygen measurements began within $15 \mathrm{~s}$. The chamber was immersed in a water bath and water in the chamber was circulated by a magnetic stir-bar in the bottom of the chamber that was separated from the fish by a plastic screen. Changes in $\mathrm{MO}_{2}$ were measured using the same probe as above. Oxygen concentration in the chamber was allowed to decrease by a minimum of $10 \%$ and then chamber was manually flushed. Measurements were repeated for approximately $1 \mathrm{~h}$ or until $\mathrm{MO}_{2}$ had decreased appreciably. The fish was then removed from the chamber and weighed before maximum $\mathrm{MO}_{2}$ measurements were made on the next fish.

Resting and maximum $\mathrm{MO}_{2}\left(\mathrm{mg} \mathrm{O}_{2} \mathrm{~kg}^{-1} \mathrm{~min}^{-1}\right)$ were calculated from the decrease in oxygen concentration in the respirometry chambers. Resting $\mathrm{MO}_{2}$ was calculated over a minimum period of approximately $500 \mathrm{~s}$. Approximately $12 \mathrm{MO}_{2}$ measurements were made overnight and the resting $\mathrm{MO}_{2}$ value was calculated as an average of the lowest three values for each fish (i.e., equivalent to a $25 \%$ quantile of the resting $\mathrm{MO}_{2}$ records). Maximum $\mathrm{MO}_{2}$ was calculated from a minimum period of approximately $50 \mathrm{~s}$ and was the highest value recorded, which typically occurred $\sim 2-5 \mathrm{~min}$ after the chase to exhaustion. Scope for $\mathrm{MO}_{2}$ was calculated by subtracting resting $\mathrm{MO}_{2}$ from maximum $\mathrm{MO}_{2}$.

\section{CARDIAC AND GILL MORPHOMETRICS OF PARR}

The ventricle and the first gill arch from left side were removed after the $f_{\text {Hmax }}$ tests $(N=12$ per group). The ventricle was halved mid-sagittally. The gill and cardiac tissues were fixed in 4\% formalin in phosphate buffered saline (PBS) for histological analyses. An additional 10 fish per group were sacrificed by blow to head 2 weeks after the swimming performance measurements to sample 
the ventricle and compare the ventricle mass to the body mass $\left(\mathrm{M}_{\mathrm{RV}}\right)$ of the fish.

Morphological assessments were made on all gill and ventricle samples ( $N=12$ per group). The formalin-fixed ventricles were dehydrated in alcohol and UltraClear (Mallinckrodt Baker Inc., Center Valley, PA, USA) series (70\% EtOH $1 \mathrm{~h}$, $94 \% \mathrm{EtOH} 1 \mathrm{~h}, 100 \% \mathrm{EtOH} 3 \times 1 \mathrm{~h}$, UltraClear $2 \times 1 \mathrm{~h}$ ) before embedding in paraffin wax. Serial sections $(5 \mu \mathrm{m})$ were cut with microtome (301-268.001, Ernst Leitz GmbH, Wetzlar, Germany) and mounted on glass slides. The sections were de-waxed with UltraClear and rehydrated with an alcohol series and distilled water prior to staining with amylase-periodic acid-Schiff (PAS; Andersen, 1975). For PAS staining the sections were incubated for $1 \mathrm{~h}$ in $1 \%$ amylase at $37^{\circ} \mathrm{C}$, rinsed with distilled water and oxidized with $1 \%$ periodic acid at room temperature for $20 \mathrm{~min}$. After oxidation the sections were stained with Schiff's reagent for $20 \mathrm{~min}$ before rinsing and dehydrating them with alcohol and UltraClear series. The sections were examined in Leica DM RXA microscope (Leica Microsystems, Wetzlar, Germany). The thickness of the compact layer was measured from each ventricle at intervals ( $\sim 100 \mu \mathrm{m}$ for parr and $\sim 300 \mu \mathrm{m}$ for post-smolt) around the perimeter. The average compact thickness was divided by the cross-section area of the ventricle.

The formalin-fixed gill tissue were similarly processed prior to staining with Mayer's hematoxylin (RAL Diagnostics, Martillac, France) and using sagittal sections along the primary gill filament to provide cross-sections of the secondary lamellae. From these sections it was possible to measure the height of secondary lamellae in contact with water. Lamellar height was measured on at least six sections for each individual and the average was used to calculate the relative lamellar height by dividing it with fish mass.

\section{TESTING AND MORPHOMETRICS OF POST-SMOLTS}

After a 15-week grow-out period in seawater (i.e., 8 months after the sorting for swimming performance), $f_{\text {Hmax }}$ of postsmolts from the poor and good swimming groups was measured as described above with slight modification. For postsmolts, heart rate was allowed to stabilize for $30 \mathrm{~min}$ at $13^{\circ} \mathrm{C}$ before the intraperitoneal injection of atropine sulfate to measure $f_{\text {Hmax }}$ ( $N=7$ for both good and poor swimmers). After the $f_{\text {Hmax }}$ measurements fish were euthanized and ventricles and gills were processed for histology as described above. The ventricular and body mass were also measured in these fish to calculate $\mathrm{M}_{\mathrm{RV}}$.

\section{DATA AND STATISTICAL ANALYSES}

Rate transition temperatures for the response of $f_{\text {Hmax }}$ to acute warming were determined from each individual fish. The lowest rate transition temperature was an Arrhenius breakpoint temperature $\left(\mathrm{T}_{\mathrm{AB}}\right)$, calculated according to Yeager and Ultsch (1989) by fitting two-segment linear regression lines to an Arrhenius plot [natural logarithm of $f_{\text {Hmax }}$ and inverse of temperature (in Kelvin)] and calculating the intersection of the lines. The next highest rate transition temperature was the breakpoint temperature of $\mathrm{Q}_{10}\left(\mathrm{~T}_{\mathrm{QB}}\right)$, which was established by first calculating the incremental $\mathrm{Q}_{10}$ of $f_{\mathrm{Hmax}}$ for each temperature step $\left(\mathrm{Q}_{10}=\right.$ $\left.\left[f_{H \max n+1} / f_{\operatorname{Hax} n}\right]^{\wedge}\left[10 /\left\{\mathrm{T}_{n+1}-\mathrm{T}_{n}\right\}\right]\right)$, where $f_{\text {Hmax } n}$ was $f_{\text {Hmax }}$ at a temperature $\mathrm{n}\left(\mathrm{T}_{n}\right)$ and $f_{\text {Hmax } n+1}$ was $f_{\text {Hmax }}$ at the next temperature $\left(\mathrm{T}_{n+1}\right) . \mathrm{T}_{\mathrm{QB}}$ was the first breakpoint in a twosegment regression analysis of these $\mathrm{Q}_{10}$ data. The next highest rate transition temperature was the temperature $\left(\mathrm{T}_{\max }\right)$ for the highest $f_{\text {Hmax }}$ value $\left(\max f_{\text {Hmax }}\right)$. The highest rate transition temperature was arrhythmia temperature $\left(\mathrm{T}_{\mathrm{arr}}\right)$, which was the lowest temperature to induced cardiac arrhythmia.

Statistical comparisons were made between poor and good swimmers, and between parr and post-smolts using Two-Way ANOVA followed by Holm-Sidak post-hoc test for $\mathrm{M}_{\mathrm{RV}}$, compact layer thickness, absolute and relative gill lamellae height, $\max f_{\text {Hmax }}$ and the rate transition temperatures $\left(\mathrm{T}_{\mathrm{AB}}, \mathrm{T}_{\mathrm{QB}}, \mathrm{T}_{\mathrm{arr}}\right.$, and $\left.\mathrm{T}_{\max }\right)$. $f_{\text {Hmax }}$ was compared for each temperature increment using Three-Way ANOVA with temperature, swimming group (good vs. poor) and age as factors. A Student's $t$-test was used to compare resting $\mathrm{MO}_{2}$, maximum level of $\mathrm{MO}_{2}$ and aerobic scope between poor and good swimmer parrs. One-Way ANOVA was also used to compare the weights and lengths of the poor and good swimmers at different time points. Data were $\log _{10}$ transformed whenever equal variance and normality assumptions were not met (compact thickness and total lamellae height). All the statistical analyses were performed with SigmaPlot 12.3 (Systat Software Inc., San Jose, CA, USA). Statistical significance for comparisons of mean values was set at $\alpha=0.05$. All values are reported as mean and S.E. unless otherwise stated.

\section{RESULTS \\ SWIMMING PERFORMANCE, RESPIRATORY CAPACITY AND MORPHOLOGY OF PARR AND POST-SMOLTS}

The screen for swimming performance segregated parr into poor $(30 \%)$, moderate $(40 \%)$, and good (30\%) swimmers. Collectively, poor swimmers swam from 13 to $49 \mathrm{~min}$ to a final swimming speed of $4.39 \pm 0.11 \mathrm{BL} \mathrm{s}^{-1}(N=960)$. Moderate swimmers swam for almost twice as long, from 49 to $77 \mathrm{~min}$, to a $55 \%$ higher final swimming speed of $6.78 \pm 0.09 \mathrm{BL} \mathrm{s}{ }^{-1}(N=1280)$. Good swimmers swam for a minimum of $73 \mathrm{~min}$ and to an undetermined final swimming speed that was $>6.78 \mathrm{BL} \mathrm{s}^{-1}(\mathrm{~N}=$ 960). Despite these differences in estimated swimming performance of parr, the body length, mass and condition factor for these performance groupings were indistinguishable (Table 1). Likewise, resting $\mathrm{MO}_{2}$, maximum $\mathrm{MO}_{2}$ and $\mathrm{MO}_{2}$ scope were indistinguishable for the good and poor swimmers (Table 1).

Compared with poor swimmers, parr that were good swimmers had a thicker compact myocardium (by 23.7\%) and significantly taller secondary gill lamellae (by 16.2\%) (Figure 1). The relative height of the lamellae was $6.8 \pm 0.4$ and $6.2 \pm 0.3 \mu \mathrm{m}$ $\mathrm{g}^{-1}$ for good and poor swimmers, respectively, and did not differ statistically.

Only minor differences in thermal tolerance existed between poor and good swimmers. All parr, independent of swimming group, could be warmed to $23^{\circ} \mathrm{C}$ without the heart becoming arrhythmic. Yet, $f_{\text {Hmax }}$ reached a significantly higher value at $21^{\circ} \mathrm{C}$ for poor swimmers compared with good swimmers, and this difference extended beyond $21^{\circ} \mathrm{C}$ for those fish hearts that did not become arrhythmic (Figure 2A, Table 2). However, the Arrhenius and $\mathrm{Q}_{10}$ break point analysis curves 
(Figures 2B,C, respectively) revealed few and only minor differences in the rate transition temperatures, with only $\mathrm{T}_{\mathrm{AB}}$ for $f_{H \max }$ being significantly different among the parr swimming groups (Figure 2B, Table 2).

The good swimmers of post-smolts had relatively larger ventricles $(17.4 \%)$ and taller secondary lamellae $(14.7 \%)$ as compared with poor swimmers (Figure 1). Furthermore, good swimmers had a $15.9 \%$ thicker compact myocardial layer (Figure 1) and the relative height of the gill lamellae was higher for good swimmers $\left(0.65 \pm 0.02\right.$ vs. $\left.0.57 \pm 0.02 \mu \mathrm{m} \mathrm{g}^{-1}\right)$. In addition, they had developed a significantly larger ventricle (17.4\%) (Figure 1). Also, similar to the parr stage, post-smolts of poor swimmers had significantly higher $f_{\text {Hmax }}$ than good swimmers at temperatures beyond $21^{\circ} \mathrm{C}$ (Figure 2A). While all post-smolts ranked as poor swimmers maintained a rhythmic heartbeat up to $24^{\circ} \mathrm{C}$, this was not the case for the good swimmers (Figure 2A). The rate transition temperatures for post-smolts did not, however, differ significantly between good and poor swimmers (Table 2 ).

When comparing the larger post-smolts with parr, $f_{\text {Hmax }}$ at any given test temperature (Figure $2 \mathbf{A}$ ) as well as $\max f_{\text {Hmax }}$ for post-smolts were significantly $(50-52 \mathrm{bpm})$ lower than that for the parr. In addition, some rate transition temperatures differed significantly between parr and post-smolts. Specifically, $\mathrm{T}_{\mathrm{AB}}$ was significantly higher and $\mathrm{T}_{\max }$ significantly lower for

Table 1 | Swimming and metabolic capacities of good and poor salmon parr swimmers measured at $12^{\circ} \mathrm{C}$.

\begin{tabular}{lcc}
\hline & Poor swimmers & Good swimmers \\
\hline Body mass (g) & $12.3 \pm 0.6$ & $11.2 \pm 0.4$ \\
Body length (BL, cm) & $10.4 \pm 0.1$ & $10.1 \pm 0.1$ \\
Condition factor & $1.08 \pm 0.01$ & $1.09 \pm 0.01$ \\
Swimming speed $\left(B L^{-1}\right)$ & $4.39 \pm 0.11$ & $>6.78 \pm 0.09 *$ \\
Resting MO $2\left(\mathrm{mg} \mathrm{kg}^{-1} \mathrm{~min}^{-1}\right)$ & $1.5 \pm 0.1$ & $1.5 \pm 0.1$ \\
$\mathrm{Max} \mathrm{MO}_{2}\left(\mathrm{mg} \mathrm{kg}^{-1} \mathrm{~min}^{-1}\right)$ & $7.8 \pm 0.2$ & $7.9 \pm 0.2$ \\
$\mathrm{MO}_{2} \mathrm{scope}\left(\mathrm{mg} \mathrm{kg}^{-1} \mathrm{~min}^{-1}\right)$ & $6.2 \pm 0.2$ & $6.3 \pm 0.2$ \\
\hline
\end{tabular}

Note: $B L s^{-1}$, body lengths per second; $\mathrm{MO}_{2}$, oxygen consumption. $N=3200$ for swimming performance and $\mathrm{N}=10$ per group for $\mathrm{MO}_{2}$ measurements.

*Indicates significant difference between poor and good swimmers. post-smolts compared with parr (Table 2) and the Arrhenius and $\mathrm{Q}_{10}$ breakpoint temperatures were also more abrupt for post-smolts (Figures 2B,C).

While body mass and fork length did not differ significantly between poor and good swimmers at parr stage, a small, but significant difference emerged between poor and good swimmer at stages thereafter. The good swimmers were heavier $(10.2-9.7 \%)$ as well as longer (2.9-3.6\%) than poor swimmers as parr (4 weeks post swim-test [wps], $N=960$ ) and as smolts ( 14 wps, $N=960$ ). After the size grading prior to seawater transfer, the good swimmers tended to grow faster than the poor swimmers and they were $7.4 \%$ heavier and $3.4 \%$ longer than poor swimmers $(29 \mathrm{wps}$, $N=28$ per group) (Figure 3 ). No mortality was recorded during the experiment.

\section{DISCUSSION}

The first aim of this study was to evaluate if Atlantic salmon parr could be sorted for swimming performance and was the swimming performance associated with cardiorespiratory performance and morphology as well as thermal tolerance. The present results revealed that it was possible to segregate parr of similar size into very distinct groups of good and poor swimmers with a simple screening test that used a $2 \mathrm{~m}$ long transparent swimming tunnel to test 200 fish at a time. Swimming performance of the good swimmers was minimally $55 \%$ better than the poor swimmers. While our intent was to measure swimming capacity, swim tests in general and in particular rapid screens such as this one do necessarily incorporate fish behaviors and willingness to swim. For example, it is possible that some fish positioned themselves in the water current to take advantage of other fish in terms of energy cost, just like human athletes do when racing competitively. Thus, while we think that the morphological and physiological associations with the swimming were most likely causative because we performed 16 independent tests to generate the fish groupings, we cannot be certain that a particular behavior (e.g., pro-active and reactive personalities) led to the morphological and physiological conditions that segregated out with the screen for swimming performance. Resolving this conundrum will require work well beyond the present study, which had as its primary aim to develop a useful test that could be used in aquaculture to screen for cardiorespiratory robustness. It is for

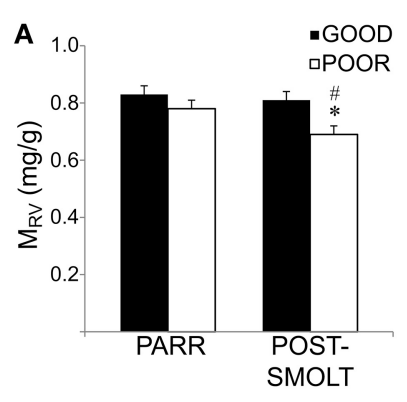

FIGURE 1 | Comparison of cardiac and gill morphometrics between swimming groups. (A) Relative ventricle mass $\left(\mathrm{M}_{\mathrm{RV}}\right)$; which is ventricle mass in $\mathrm{mg}$ divided by mass of fish in grams, (B) relative thickness of the compact layer in ventricle which is calculated as thickness/ventricle cross-section area
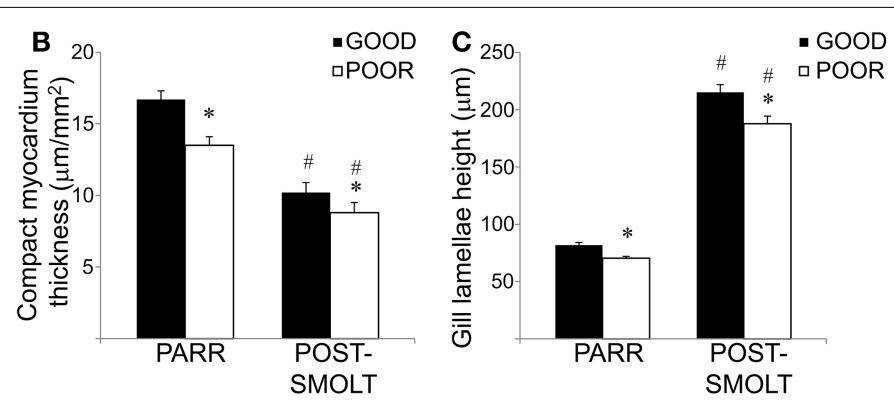

of ventricle, and (C) height of the secondary gill lamellae. *Indicates significant differences between good and poor swimming groups and the \# indicates significant difference between parr and post-smolt in their respective swimming groups. $N=12$ for parr and $N=7$ for post-smolt per group. 


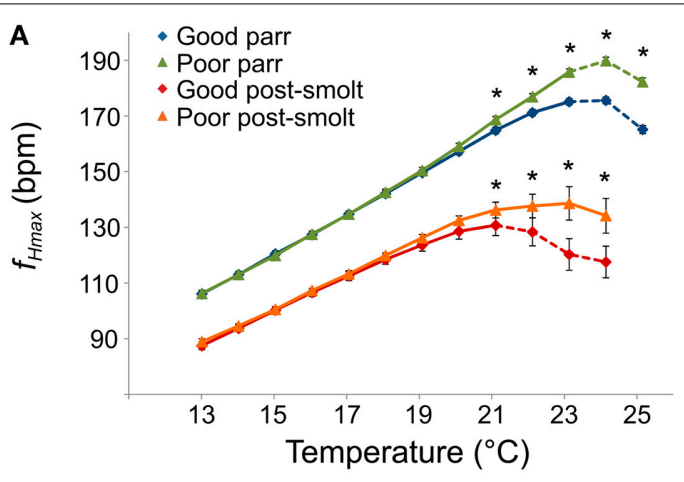

B

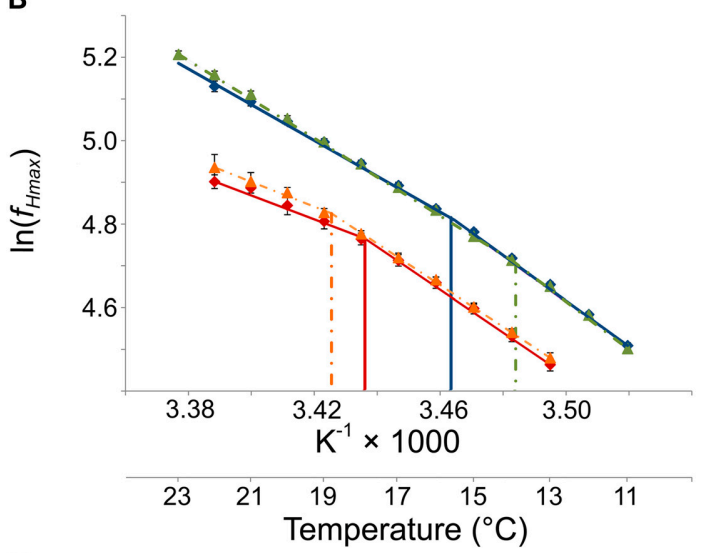

C

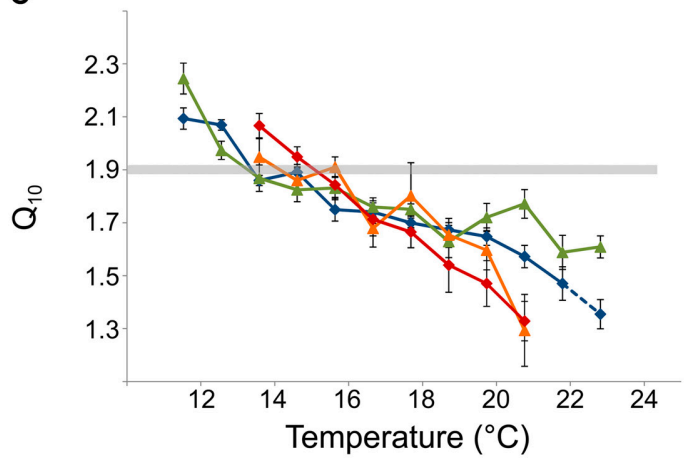

FIGURE 2 | (A) Maximum heart rates $\left(f_{\text {Hmax }}\right) \pm$ S.E. of the swim capacity groupings during acute warming. ${ }^{*}$ indicates significant $(p<0.05)$ difference between good and poor swimmers. The parrs had significantly higher heart rate in each temperature point than post-smolt ( $F=48, p<0.05)$. The hatched line indicates the temperature where the first arrhythmias were observed. (B) Arrhenius plot of maximum heart rate $\left(f_{\text {Hmax }}\right)$ of good and poor swimmers. The vertical lines indicate an Arrhenius break point temperature $\left(T_{A B}\right)$ for the swim capacity groupings. (C) Average $\mathrm{Q}_{10} \pm \mathrm{SE}$ of maximum heart rate during acute warming. The gray bar $\left(\mathrm{Q}_{10}=1.9\right)$ indicates the rate transition temperature where maximum heart rate starts an abrupt reduction in its exponential dependence with temperature, which is the $\mathrm{Q}_{10}$ break point temperature. In each figure, $N=12$ per group for parr and $N=7$ per group for post-smolt.

this reason that we use the term swimming performance rather than capacity to report the results of the screening test.

From an aquaculture perspective, the second aim of this study was to identify any features of cardiorespiratory robustness and evaluate whether or not any of the differences at parr stage persisted after a 15-week grow-out as post-smolts in seawater. The higher swimming performance of good swimmers was associated with the thicker cardiac compact layer and taller gill secondary lamellae, but with similar resting $\mathrm{MO}_{2}$, maximum $\mathrm{MO}_{2}$, and aerobic scope at $11^{\circ} \mathrm{C}$. Importantly, these morphometric features were retained as post-smolts and additionally the good swimmers had developed a relatively larger ventricle. Furthermore, poor swimmers had a higher max $f_{\text {Hmax }}$ without conferring any appreciable benefit to their upper thermal tolerance to acute warming; $\mathrm{T}_{\mathrm{QB}}$ and $\mathrm{T}_{\text {arr }}$ were similar compared with good swimmers and $\mathrm{T}_{\mathrm{AB}}$ showed only a minor difference. Of great importance to aquaculture was the discovery that better growth at the postsmolt stage was associated with good swimming performance. The potential application of these results to commercial aquaculture of Atlantic salmon is applying a simple screen for swimming performance at early age to improve robustness characteristics well beyond the smolt stage. Indeed, the morphological features and higher $f_{\text {Hmax }}$ that distinguished good and poor swimming in $11 \mathrm{~g}$ parr persisted for 8 months and 15 weeks after seawater transfer. Moreover, good swimmers had improved growth rate. The disease-free aquarium environment used here did not, however, allow us to evaluate potential effects on fish survival. In fact, we observed no mortality. Nevertheless, a previous study with Atlantic salmon found that good swimmers had better survival than poor swimmers when challenged with a viral disease infection after smolt transfer (Castro et al., 2013b).

Beyond the novel insights of morphological differences in cardiorespiratory system as well as similarity of thermal tolerance between good and poor swimmers, the present findings support earlier information on the general cardiorespiratory associations when fish are sorted according to swimming performance. For example, good swimmers of rainbow trout had higher active metabolic rate and in vivo maximum cardiac output, but similar routine metabolic rate as poor swimmers at $16^{\circ} \mathrm{C}$ (Claireaux et al., 2005). In the present study, we do not see any difference in the metabolic rate measurements and have no explanation for this difference. Good swimmers in the earlier study also had a higher in vivo maximum cardiac output (the volume of blood heart is pumping per time unit) than poor swimmers, with heart rate and stroke volume both being numerically lower (but not reaching statistical significance) in the poor swimmers. This result is consistent with the present observation of a larger ventricular mass in good swimmers and similar $f_{\text {Hmax }}$ for good and poor swimmers at cold temperatures. The previous study also showed that cardiorespiratory traits associated with better swimming performance can be retained in rainbow trout after a 9-month common garden grow-out in freshwater. Here, some but not all differences observed at the parr stage were retained in the post-smolt stage. Collectively, these results suggest that long-term experiments to adulthood are worthwhile to test how long such distinctions are retained. Also, we used an arbitrary $30 \%$ cutoff and do not know whether a greater proportion of the fish share these traits or to what degree the traits associated with poor swimmers were driven by a smaller proportion of the population. Thus, from an aquaculture perspective, a commercially viable screening for robustness should not cull too many parr and it would be useful to study if these traits are heritable, which 
Table 2 | Comparison of rate transition temperatures $\left({ }^{\circ} \mathrm{C}\right)$ derived from maximum heart rate $\left(f_{H \max }\right)$.

\begin{tabular}{|c|c|c|c|c|}
\hline & \multicolumn{2}{|c|}{ Parr } & \multicolumn{2}{|c|}{ Post-smolt } \\
\hline $\mathrm{T}_{\mathrm{QB}}$ & $15.8 \pm 0.4^{\mathrm{a}}$ & $15.1 \pm 0.4^{a *}$ & $16.8 \pm 0.4^{\mathrm{A}}$ & $16.3 \pm 0.3^{A}$ \\
\hline $\mathrm{T}_{\text {arr }}$ & $26.1 \pm 0.4^{\mathrm{a}}$ & $26.0 \pm 0.4^{a}$ & $25.3 \pm 0.7^{A}$ & $25.3 \pm 0.7^{A}$ \\
\hline$T_{\max }$ & $24.3 \pm 0.4^{a *}$ & $24.4 \pm 0.2^{a *}$ & $21.1 \pm 0.4^{\mathrm{A}}$ & $21.9 \pm 0.4^{\mathrm{A}}$ \\
\hline
\end{tabular}

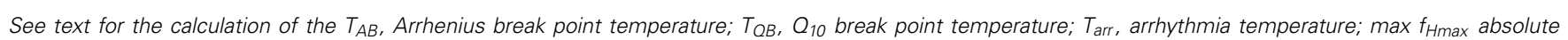

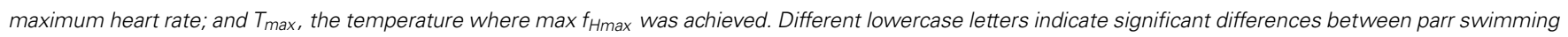

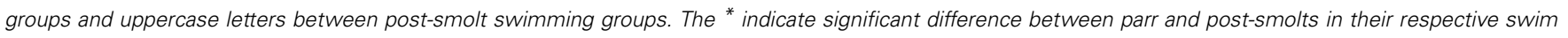
groups.

$N=12$ for parr and $N=7$ for post-smolt per group.

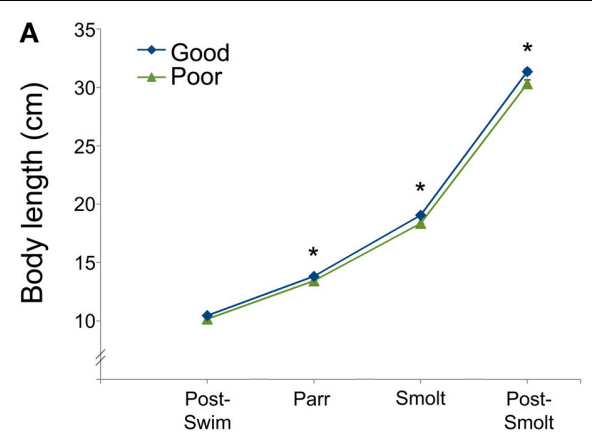

FIGURE 3 | The average (A) body length \pm SE and (B) body mass \pm SE of poor and good swimmers when tested at different time points after the swimming endurance experiment; directly after swimming (Post-Swim, $N=960$ per group), at parr

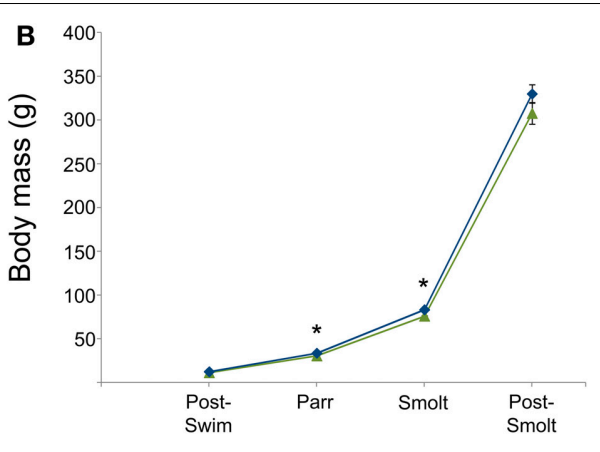

stage 4 weeks post-swimming (wps, $N=960$ per group), at smolt stage 14 wps ( $N=960$ per group), at post-smolt stage ( $\boldsymbol{N}=\mathbf{2 8}$ per group). *Indicates significant difference between swimming groups. would allow genetic selection as a strategy to improve cardiorespiratory robustness of the broodstock. Evidence already exists for heritability of thermal and swimming capacities (Garenc et al., 1998; Anttila et al., 2013b; Muñoz et al., 2014). To what degree heritable traits might be masked by the environmental plasticity of the cardiorespiratory system is equally fascinating.

Gills are regarded as a plastic organ and here taller gill secondary lamellae were associated with a greater swimming performance. Brauner et al. (2011) showed that exercise training in crucian carp (Carassius carassius) increased the lamellar surface area in contact with water, but without altering critical swimming speed, whereas goldfish developed a larger lamellar surface area and a higher swimming capacity when exposed to hypoxia (Fu et al., 2011). Of course, surgically removing gill lamellae has been shown to reduce critical swimming speed in rainbow trout (Duthie and Hughes, 1987). Thus, there are clear evidences for plastic responses of the gill with variable consequences to swimming performance. However, the present study is the first to relate it to a screen test for swimming performance.

The fish heart is similarly considered plastic within a species with respect to both its form and function (Gamperl and Farrell, 2004). For example, rainbow trout ranked as good swimmers had a more elongated ventricle and this translated to a greater cardiac output (Claireaux et al., 2005). By comparison, wild cohorts of
Atlantic salmon have a more pyramidal ventricle compared with farmed fish (Poppe et al., 2003). The present work extends this idea by showing that good swimmers had a significantly larger relative ventricular mass at the post-smolt stage. This difference in ventricular mass could be largely a result of the greater proportion of compact myocardium, as seen in both the parr and post-smolt stage, which could supply the heart with a larger coronary circulation and assist contractile power. The finding that good swimmers have thicker compact myocardium is not surprising given the positive correlation found between ventricular volume and compact thickness in both rainbow trout and Atlantic salmon (Poupa et al., 1974) and that compact thickness is related to a higher athletic capacity of sockeye salmon (Eliason et al., 2011). Farmed gilthead seabream (Sparus aurata), European seabass (Dicentrarchus labrax), and Senegalese sole (Solea senegalensis) all had a thinner compact myocardium compared with their wild conspecifics (Pombo et al., 2012), suggesting a selective advantage for compact myocardium in the wild.

Another novel discovery was that the grouping according to swimming performance was not associated with any major difference in the acute upper thermal tolerance of parr or post-smolt, as indicated by $f_{\text {Hmax }}$. This finding has an important implication for aquaculture in that selecting fish with a high swimming performance could benefit cardiorespiratory robustness without 
compromising upper thermal tolerance. The higher $f_{\text {Hmax }}$ values at a given temperature of parr as compared to post-smolt were expected given the size and developmental difference (postsmolts were $\sim 26$ times heavier). An inverse relationship between $f_{H}$ and body mass is common among vertebrates (Lucas, 1994; Lillywhite et al., 1999) as is the reduction of the heart rate during development (Barrionuevo and Burggren, 1999). The $f_{\text {Hmax }}$ measured after atropine injection in the present study show good agreement with the literature. Previously, Wood et al. (1979) observed a $f_{\text {Hmax }}$ of $\sim 110 \mathrm{bpm}$ at $20^{\circ} \mathrm{C}$ in $94-550 \mathrm{~g}$ rainbow trout, which is comparable to current value of $130 \mathrm{bpm}$ of $300 \mathrm{~g}$ postsmolts. The $f_{\text {Hmax }}$ of $157 \mathrm{bpm}$ at $20^{\circ} \mathrm{C}$ for $11 \mathrm{~g}$ parr is again comparable to $f_{\text {Hmax }}(\sim 140 \mathrm{bpm})$ of $10 \mathrm{~g}$ coho salmon (Casselman et al., 2012).

For juvenile salmonids, $\mathrm{T}_{\mathrm{AB}}$ is a reasonable index for $\mathrm{T}_{\mathrm{opt}}$ for aerobic scope while $\mathrm{T}_{\text {arr }}$ is a good index of upper thermal tolerance (Casselman et al., 2012; Anttila et al., 2013a). Here $\mathrm{T}_{\mathrm{AB}}\left(\sim 15^{\circ} \mathrm{C}\right)$ of $11 \mathrm{~g}$ parr was comparable to the optimum growth temperature of Atlantic salmon parr $\left(15.9^{\circ} \mathrm{C}\right.$; Elliott and Hurley, 1997) and $\mathrm{T}_{\text {arr }}\left(26^{\circ} \mathrm{C}\right)$ was below their incipient lethal temperature of $29^{\circ} \mathrm{C}$ (Beitinger et al., 2000). The slightly higher $\mathrm{T}_{\mathrm{AB}}$ in post-smolts than in parr contrasts with juvenile turbot (Scophthalmus maximus) where the optimum temperature for growth rate decreases in larger fish (Imsland et al., 1996). The thermal tolerance window can be plastic and is expected to change with life stage (Pörtner and Farrell, 2008) and with thermal acclimation (Ferreira et al., 2014), which might help to explain the differences between parr and post-smolts here. For aquaculture purposes, the higher $\mathrm{T}_{\mathrm{AB}}$ of good swimmers than poor swimmers at parr stage might also have a practical application as the good swimmers might be able to handle higher rearing temperatures than poor swimmers, an aspect worth further investigation.

An interesting discovery in the present study was the lower $f_{\text {Hmax }}$ in the good swimmers at supra-optimal temperatures ( $>$ $21^{\circ} \mathrm{C}$ ). This result needs to be considered in the context that cardiac output in fish can be increased through cardiac stroke volume as well as $f_{H}$ (Farrell, 1991). Indeed, a larger cardiac stroke volume was observed earlier for good swimmers when maximum cardiac performance was tested in situ for farmed rainbow trout heart (Claireaux et al., 2005). Also, Franklin and Davie (1992) showed that rainbow trout with a larger ventricle have a larger stroke volume. Therefore, the elevated $f_{\text {Hmax }}$ in poor swimmers may be directly related to their smaller ventricular mass (and perhaps a lower cardiac stroke volume) and a thinner compact myocardium compared with good swimmers.

In conclusion, important physiological and morphological differences between poor and good swimmers persisted for at least 8 months of rearing, suggesting that early screening for cardiorespiratory fitness traits in Atlantic salmon parr may represent a promising approach for salmon production.

\section{AUTHOR CONTRIBUTIONS}

Sven Martin Jørgensen, Gerrit Timmerhaus, and Harald Takle performed the sorting of the fish for swimming performance. Katja Anttila and Matthew T. Casselman performed the heart rate and $\mathrm{MO}_{2}$ measurements of parrs and Sven Martin Jørgensen and Harald Takle performed heart rate measurements of post-smolts.
Sven Martin Jørgensen, Gerrit Timmerhaus, and Harald Takle did the sampling of the fish at different time points for weight and length calculations. Katja Anttila did the morphological assessments. Katja Anttila analyzed the data of all the measurements. Harald Takle and Anthony P. Farrell initiated and provided the overall direction of the study and participated in writing the manuscript with considerable input from Katja Anttila and Sven Martin Jørgensen. All the authors have revised work critically for important intellectual content, have approved the version to be published and agreed to be accountable for all aspects of the work.

\section{ACKNOWLEDGMENTS}

We would like to thank Arild Linseth for building the swim tunnel and technical support during the fish experiment. This study was supported by the Research Council of Norway RCN (grant number: 225219/E40), the Fishery and Aquaculture Industry Research Fund (grant number: 900870), and a research grant to Katja Anttila from the Kone Foundation. Anthony P. Farrell holds a Canada Research Chair. This publication is supported by COST Action FA1304 "Swimming of fish and implications for migration and aquaculture (FITFISH)".

\section{REFERENCES}

Andersen, P. (1975). Capillary density in skeletal muscle of man. Acta Physiol. Scand. 95, 203-205. doi: 10.1111/j.1748-1716.1975.tb10043.x

Anttila, K., Casselman, M. T., Schulte, P. M., and Farrell, A. P. (2013a). Optimum temperature in juvenile salmonids: connecting subcellular indicators to tissue function and whole-organism thermal optimum. Physiol. Biochem. Zool. 86, 245-256. doi: 10.1086/669265

Anttila, K., Couturier, C. S., Øverli, Ø., Johnsen, A., Marthinsen, G., Nilsson, G. E., et al. (2014). Atlantic salmon show capability for cardiac acclimation to warm temperatures. Nat. Commun. 5, 4252. doi: 10.1038/ncomms5252

Anttila, K., Dhillon, R. S., Boulding, E. G., Farrell, A. P., Glebe, B. D., Elliott, J. A. K., et al. (2013b). Variation in temperature tolerance among families of Atlantic salmon (Salmo salar L.) is associated with hypoxia tolerance, ventricle size and myoglobin level. J. Exp. Biol. 216, 1183-1190. doi: 10.1242/jeb.080556

Anttila, K., Järvilehto, M., and Mänttäri, S. (2008). The swimming performance of brown trout and whitefish: the effects of exercise on $\mathrm{Ca}^{2+}$ handling and oxidative capacity of swimming muscles. J. Comp. Physiol. B 178, 465-475. doi: 10.1007/s00360-007-0239-3

Anttila, K., Jokikokko, E., Erkinaro, J., Järvilehto, M., and Mänttäri, S. (2011). Effects of training on functional variables of muscles in reared Atlantic salmon Salmo salar smolts: connection to downstream migration pattern. J. Fish Biol. 78, 552-566. doi: 10.1111/j.1095-8649.2010.02871.x

Barrionuevo, W. R., and Burggren, W. W. (1999). $\mathrm{O}_{2}$ consumption and heart rate in developing zebrafish (Danio rerio): influence of temperature and ambient $\mathrm{O}_{2}$. Am. J. Physiol. 276, R505-R513.

Beitinger, T. L., Bennett, W. A., and McCauley, R. W. (2000). Temperature tolerances of North American freshwater fishes exposed to dynamic changes in temperature. Environ. Biol. Fish. 58, 237-275. doi: 10.1023/A:1007676325825

Brauner, C. J., Matey, V., Zhang, W., Richards, J. G., Dhillon, R., Cao, Z.-D., et al. (2011). Gill remodeling in crucian carp during sustained exercise and the effect on subsequent swimming performance. Physiol. Biochem. Zool. 84, 535-542. doi: $10.1086 / 662664$

Casselman, M. T., Anttila, K., and Farrell, A. P. (2012). Using maximum heart rate as a rapid screening tool to determine optimum temperature for aerobic scope in Pacific salmon Oncorhynchus spp. J. Fish Biol. 80, 358-377. doi: 10.1111/j.1095-8649.2011.03182.x

Castro, V., Grisdale-Helland, B., Helland, S. J., Kristensen, T., Jørgensen, S. M., Helgerud, J., et al. (2011). Aerobic training stimulates growth and promotes disease resistance in Atlantic salmon (Salmo salar). Comp. Biochem. Physiol. A Mol. Integr. Physiol. 160, 278-290. doi: 10.1016/j.cbpa.2011.06.013

Castro, V., Grisdale-Helland, B., Helland, S. J., Torgersen, J., Kristensen, T., Claireaux, G., et al. (2013a). Cardiac molecular acclimation mechanisms 
in response to swimming induced exercise in Atlantic salmon. PLoS ONE, 8:e55056. doi: 10.1371/journal.pone.0055056

Castro, V., Grisdale-Helland, B., Jørgensen, S. M., Helgerud, J., Claireaux, G., Farrell, A. P., et al. (2013b). Disease resistance is related to inherent swimming performance in Atlantic salmon. BMC Physiol. 13:1. doi: 10.1186/14726793-13-1

Chen, Z., Anttila, K., Wu, J., Whitney, C. K., Hinch, S. G., and Farrell, A. P. (2013). Optimum and maximum temperatures of sockeye salmon (Oncorhyncus nerka) populations hatched at different temperatures. Can. J. Zool. 91, 265-274. doi: 10.1139/cjz-2012-0300

Claireaux, G., McKenzie, D. J., Genge, A. G., Chatelier, A., Aubin, J., and Farrell, A P. (2005). Linking swimming performance, cardiac pumping ability and cardiac anatomy in rainbow trout. J. Exp. Biol. 208, 1775-1784. doi: 10.1242/jeb.01587

Clark, T. D., Jeffries, K. M., Hinch, S. G., and Farrell, A. P. (2011). Exceptional aerobic scope and cardiovascular performance of pink salmon (Oncorhynchus gorbuscha) may underlie resilience in a warming climate. J. Exp. Biol. 214 3074-3081. doi: 10.1242/jeb.060517

Davison, W. (1997). The effects of exercise training on teleost fish, a review of recent literature. Comp. Biochem. Physiol. 117A, 67-75. doi: 10.1016/S03009629(96)00284-8

Duthie, G. G., and Hughes, G. M. (1987). The effects of reduced gill area and hyperoxia on the oxygen consumption and swimming speed of rainbow trout. J. Exp. Biol. 127, 349-354

Eliason, E. J., Clark, T. D., Hague, M. J., Hanson, L. M., Gallagher, Z. S., Jeffries, K. M., et al. (2011). Differences in thermal tolerance among sockeye salmon populations. Science 322, 109-112. doi: 10.1126/science.1199158

Eliason, E. J., Clark, T. D., Hinch, S. G., and Farrell, A. P. (2013). Cardiorespiratory collapse at high temperature in swimming adult sockeye salmon. Conserv. Physiol. 1:cot008. doi: 10.1093/conphys/cot008

Elliott, J. M., and Hurley, M. A. (1997). A functional model for maximum growth of Atlantic Salmon parr, Salmo salar, from two populations in northwest England. Funct. Ecol. 11, 592-603. doi: 10.1046/j.1365-2435.1997.00130.x

Farrell, A. P. (1991). From hagfish to tuna: a perspective on cardiac function in fish. Physiol. Zool. 64, 1137-1164.

Farrell, A. P. (2007). Cardiorespiratory performance during prolonged swimming tests with salmonids: a perspective on temperature effects and potentia analytical pitfalls. Philos. Trans. R. Soc. B 362, 2017-2030. doi: 10.1098/rstb. 2007.2111

Farrell, A. P. (2009). Environment, antecedents and climate change: lessons from the study of temperature physiology and river migration of salmonids. J. Exp. Biol. 212, 3771-3780. doi: 10.1242/jeb.02367

Farrell, A. P., Johansen, J. A., Steffensen, J. F., Moyes, C. D., West, T. G., and Suarez, R. K. (1990). Effects of exercise training and coronary ablation on swimming performance, heart size, and cardiac enzymes in rainbow trout, Oncorhynchus mykiss. Can. J. Zool. 68, 1174-1179. doi: 10.1139/z90-174

Farrell, A. P., Johansen, J. A., and Suarez, R. K. (1991). Effects of exercise-training on cardiac performance and muscle enzymes in rainbow trout, Oncorhynchus mykiss. Fish Physiol. Biochem. 9, 303-312. doi: 10.1007/BF02265151

Farrell, A. P., Lee, C. G., Tierney, K., Hodaly, A., Clutterham, S., Healey, M. C., et al. (2003). Field-based measurements of oxygen uptake and swimming performance with adult Pacific salmon using a mobile respirometer swim tunnel. J. Fish. Biol. 62, 64-84. doi: 10.1046/j.1095-8649.2003.00010.x

Ferreira, E. O., Anttila, K., and Farrell, A. P. (2014). Thermal optima and tolerance in the eurythermic goldfish (Carassius auratus): relationships between whole animal aerobic capacity and maximum heart rate. Physiol. Biochem. Zool. 87, 599-611. doi: 10.1086/677317

Franklin, C. E., and Davie, P. S. (1992). Sexual maturity can double heart mass and cardiac power output in male rainbow trout. J. Exp. Biol. 171, 139-148.

Fry, F. E. J. (1947). Effects of the environment on animal activity. Pub. Ont. Fish. Res. Lab. 68, 1-62.

Fu, S.-J., Brauner, C. J., Cao, Z.-D., Richards, J. G., Peng, J.-L., Dhillon, R. S., et al. (2011). The effect of acclimation to hypoxia and sustained exercise on subsequent hypoxia tolerance and swimming performance in goldfish (Carassius auratus). J. Exp. Biol. 214, 2080-2088. doi: 10.1242/jeb.053132

Gallaugher, P. E., Thorarensen, H., Kiessling, A., and Farrell, A. P. (2001). Effects of high intensity exercise training on cardiovascular function, oxygen uptake, internal oxygen transport and osmotic balance in chinook salmon (Oncorhynchus tshawytscha) during critical speed swimming. J. Exp. Biol. 204, 2861-2872.
Gamperl, A. K., and Farrell, A. P. (2004). Cardiac plasticity in fishes: environmental influences and intraspecific differences. J. Exp. Biol. 207, 2539-2550. doi: 10.1242/jeb.01057

Gamperl, A. K., Swafford, B. L., and Rodnick, K. J. (2011). Elevated temperature, per se, does not limit the ability of rainbow trout to increase stroke volume. J. Therm. Biol. 36, 7-14. doi: 10.1016/j.jtherbio.2010.08.007

Garenc, C., Silversides, F. G., and Guderley, H. (1998). Burst swimming and its enzymatic correlates in the threespine stickleback (Gasterosteus aculeatus): fullsib heritabilities. Can. J. Zool. 76, 680-688. doi: 10.1139/cjz-76-4-680

Hyvärinen, P., and Rodewald, P. (2013). Enriched rearing improves survival of hatchery-reared Atlantic salmon smolts during migration in the River Tornionjoki. Can. J. Fish. Aquat. Sci. 70, 1386-1395. doi: 10.1139/cjfas2013-0147

Imsland, A. K., Sunde, L. M., Folkvord, A., and Stefansson, S. O. (1996). The interaction of temperature and fish size on growth of juvenile turbot. J. Fish Biol. 49, 926-940. doi: 10.1111/j.1095-8649.1996.tb00090.x

Iversen, M., Finstad, B., McKinley, R. S., Eliassen, R. A., Carlsen, K. T., and Evjen, T. (2005). Stress responses in Atlantic salmon (Salmo salar L.) smolts during commercial well boat transports, and effects on survival after transfer to sea. Aquaculture 243, 373-382. doi: 10.1016/j.aquaculture.2004.10.019

Kristensen, T., Haugen, T. O., Rosten, T., Fjellheim, A., Atland, A., and Rosseland, B. O. (2012a). Effects of production intensity and production strategies in commercial Atlantic salmon smolt (Salmo salar L.) production on subsequent performance in the early sea stage. Fish Physiol. Biochem. 38, 273-282. doi: 10.1007/s10695-011-9566-0

Kristensen, T., Urke, H. A., Poppe, T., and Takle, H. (2012b). Atrial natriuretic peptide levels and heart morphology in migrating Atlantic salmon (Salmo salar) smolts from 4 rivers with different environmental conditions. Aquaculture 362-363, 172-176. doi: 10.1016/j.aquaculture.2011.08.003

Lillywhite, H. B., Zippel, K. C., and Farrell, A. P. (1999). Resting and maximal heart rates in ectothermic vertebrates. Comp. Biochem. Physiol. 124A, 369-382. doi: 10.1016/S1095-6433(99)00129-4

Lucas, M. C. (1994). Heart rate as an indicator of metabolic rate and activity in adult Atlantic salmon, Salmo salar. J. Fish Biol. 44, 889-903. doi: 10.1111/j.10958649.1994.tb01262.x

Muñoz, N. J., Anttila, K., Chen, Z., Heath, J. W., Farrell, A. P., and Neff, B. D. (2014). Indirect genetic effects underlie oxygen-limited thermal tolerance within a coastal population of chinook salmon. Proc. R. Soc. B 281, 1789. doi: 10.1098/rspb.2014.1082

Peake, S. J., and Farrell, A. P. (2005). Postexercise physiology and repeat performance behaviour of free-swimming smallmouth bass in an experimental raceway. Physiol. Biochem. Zool. 78, 801-807. doi: 10.1086/432148

Peake, S. J., and Farrell, A. P. (2006). Fatigue is a behavioural response in respirometer-confined smallmouth bass. J. Fish Biol. 68, 1742-1755. doi: 10.1111/j.0022-1112.2006.01052.x

Pombo, A., Blasco, M., and Climent, V. (2012). The status of farmed fish hearts: an alert to improve health and production in three Mediterranean species. Rev. Fish Biol. Fish. 22, 779-789. doi: 10.1007/s11160-012-9259-5

Poppe, T. T., Johansen, R., Gunnes, G., and Torud, B. (2003). Heart morphology in wild and farmed Atlantic salmon Salmo salar and rainbow trout Oncorhynchus mykiss. Dis. Aquat. Org. 57, 103-108. doi: 10.3354/dao057103

Pörtner, H. O. (2010). Oxygen- and capacity-limitation of thermal tolerance: a matrix for integrating climate-related stressor effects in marine ecosystems. J. Exp. Biol. 213, 881-893. doi: 10.1242/jeb.037523

Pörtner, H. O., and Farrell, A. P. (2008). Physiology and climate change. Science 322, 690-692. doi: 10.1126/science.1163156

Poupa, O., Gesser, H., Jonsson, S., and Sullivan, L. (1974). Coronary-supplied compact shell of ventricular myocardium in salmonids: growth and enzyme pattern. Comp. Biochem. Physiol. 48A, 85-95. doi: 10.1016/0300-9629(74)90856-1

Sandblom, E., Cox, G. K., Perry, S. F., and Farrell, A. P. (2009). The role of venous capacitance, circulating catecholamines, and heart rate in the hemodynamic response to increased temperature and hypoxia in the dogfish. Am. J. Physiol. Reg. Integr. Comp. Physiol. 296, R1547-R1556. doi: 10.1152/ajpregu. 90961.2008

Specker, J. L., and Schreck, C. B. (1980). Stress responses to transportation and fitness for marine survival in coho salmon (Oncorhynchus kisutch) smolts. Can. J. Fish. Aquat. Sci. 37, 765-769. doi: 10.1139/f80-102

Steinhausen, M. F., Sandblom, E., Eliason, E. J., Verhille, C., and Farrell, A. P. (2008). The effect of acute temperature increases on the cardiorespiratory 
performance of resting and swimming sockeye salmon (Oncorhynchus nerka). J. Exp. Biol. 211, 3915-3926. doi: 10.1242/jeb.019281

Takle, H., and Castro, V. (2013). "Molecular adaptive mechanisms in the cardiac muscle of exercised fish," in Swimming Physiology of Fish, eds A. P. Palstra and J. V. Planas (Berlin Heidelberg: Springer-Verlag), 257-274.

Wood, C. M., Pieprzak, P., and Trott, J. N. (1979). The influence of temperature and anaemia on the adrenergic and cholinergic mechanisms controlling heart rate in the rainbow trout. Can. J. Zool. 57, 2440-2447. doi: 10.1139/z79-316

Yeager, D. P., and Ultsch, G. R. (1989). Physiological regulation and conformation: a BASIC program for the determination of critical points. Physiol. Zool. 62, 888-907.

Conflict of Interest Statement: The authors declare that the research was conducted in the absence of any commercial or financial relationships that could be construed as a potential conflict of interest.
Received: 21 August 2014; accepted: 26 November 2014; published online: 16 December 2014.

Citation: Anttila K, Jørgensen SM, Casselman MT, Timmerhaus G, Farrell AP and Takle $H$ (2014) Association between swimming performance, cardiorespiratory morphometry, and thermal tolerance in Atlantic salmon (Salmo salar L.). Front. Mar. Sci. 1:76. doi: 10.3389/fmars.2014.00076

This article was submitted to Aquatic Physiology, a section of the journal Frontiers in Marine Science.

Copyright (C) 2014 Anttila, Jørgensen, Casselman, Timmerhaus, Farrell and Takle. This is an open-access article distributed under the terms of the Creative Commons Attribution License (CC BY). The use, distribution or reproduction in other forums is permitted, provided the original author(s) or licensor are credited and that the original publication in this journal is cited, in accordance with accepted academic practice. No use, distribution or reproduction is permitted which does not comply with these terms. 